\title{
Suppression of erythroid development in vitro by Plasmodium vivax
}

\author{
Tasanee Panichakul ${ }^{1 *}$, Witchuda Payuhakrit ${ }^{2}$, Panyu Panburana ${ }^{3}$, Chokdee Wongborisuth ${ }^{4}$, Suradej Hongeng ${ }^{5}$ and \\ Rachanee Udomsangpetch ${ }^{2,6}$
}

\begin{abstract}
Background: Severe anaemia due to dyserythropoiesis has been documented in patients infected with Plasmodium vivax, however the mechanism responsible for anaemia in vivax malaria is poorly understood. In order to better understand the role of $P$. vivax infection in anaemia the inhibition of erythropoiesis using haematopoietic stem cells was investigated.
\end{abstract}

Methods: Haematopoietic stem cells/CD34 ${ }^{+}$cells, isolated from normal human cord blood were used to generate growing erythroid cells. Exposure of $\mathrm{CD}_{3} 4^{+}$cells and growing erythroid cells to $P$. vivax parasites either from intact or lysed infected erythrocytes (IE) was examined for the effect on inhibition of cell development compared with untreated controls.

Results: Both lysed and intact infected erythrocytes significantly inhibited erythroid growth. The reduction of erythroid growth did not differ significantly between exposure to intact and lysed IE and the mean growth relative to unexposed controls was $59.4 \pm 5.2$ for lysed IE and $57 \pm 8.5 \%$ for intact IE. Interestingly, CD34 ${ }^{+}$cells/erythroid progenitor cells were susceptible to the inhibitory effect of $P$. vivax on cell expansion. Exposure to $P$. vivax also inhibited erythroid development, as determined by the reduced expression of glycophorin A (28.1\%) and CD 71 (43.9\%). Moreover, vivax parasites perturbed the division of erythroid cells, as measured by the Cytokinesis Block Proliferation Index, which was reduced to $1.35 \pm 0.05$ ( $P$-value $<0.01)$ from a value of $2.08 \pm 0.07$ in controls. Neither TNF-a nor IFN-g was detected in the culture medium of erythroid cells treated with $P$. vivax, indicating that impaired erythropoiesis was independent of these cytokines.

Conclusions: This study shows for the first time that $P$. vivax parasites inhibit erythroid development leading to ineffective erythropoiesis and highlights the potential of $P$. vivax to cause severe anaemia.

Keywords: Plasmodium vivax, Erythropoiesis, Haematopoietic stem cells, Anaemia

\section{Background}

Anaemia has frequently been associated with severe malaria and is believed to contribute to the morbidity and mortality of this disease. Most published reports on malaria-associated anaemia focus on Plasmodium falciparum with Plasmodium vivax being less well studied [1]. However, growing evidence from several geographic regions has demonstrated that $P$. vivax malaria is associated with a higher frequency and more severe anaemia [2-12]. Several cases of patients infected with $P$. vivax

\footnotetext{
* Correspondence: tasanee_p@yahoo.com

${ }^{1}$ Faculty of Science and Technology, Suan Dusit Rajabhat University, 204/3

Sirindhorn Rd., Bangplat, Bangkok, 10700, Thailand

Full list of author information is available at the end of the article
}

that resulted in severe disease and death were found to have syndromes resembling those commonly observed with falciparum malaria $[8,13,14]$. Although the underlying causes of severe malarial anaemia are multifactorial, major causes are the destruction of parasitized erythrocytes and ineffective erythropoiesis or dyserythropoiesis. In vivax malaria patients with anaemia red cells in blood film are usually normochromic and normocytic with the absolute reticulocyte count not elevated [15]. However, changes in haemoglobin concentrations are associated with continuing parasitaemia during infection of $P$. vivax in patients with anaemia [6]. In addition, $P$. vivax has been observed in the bone marrow of patients who exhibited dyserythropoiesis [15] and one

\section{Biomed Central}

(c) 2012 Panichakul et al.; licensee BioMed Central Ltd. This is an Open Access article distributed under the terms of the Creative Commons Attribution License (http://creativecommons.org/licenses/by/2.0), which permits unrestricted use, distribution, and reproduction in any medium, provided the original work is properly cited. 
case of $P$. vivax malaria in Southeast Asia displayed pancytopaenia in blood and bone marrow [16]. Investigation by light and electron microscopy of marrow aspirates from four Thai patients with $P$. vivax malaria and anaemic symptoms revealed morphological evidence of dyserythropoiesis and the presence of erythroblasts at various stages of degradation within the cytoplasm of macrophages [17]. It seems likely that vivax malaria infection was associated with an activation of the pro-inflammatory response and cytokine imbalance [18] and experimental findings in mice are consistent with a role for TNF-a in the dyserythropoietic changes in malaria [19]. Other mechanisms have also been suggested, including alterations in IFN-g, IL-12, IL-6, IL-1, reactive oxygen species, nitric oxide, macrophage dysfunction, or a direct effect of parasites (or parasite products) on the bone marrow [15,20-22]. However, the mechanism responsible for anaemia in vivax malaria remains poorly understood. Here, haematopoietic stem cells (HSCs)/ $\mathrm{CD}_{3} 4^{+}$from normal human cord blood were used to generate growing erythroid cells (gEC) to investigate the effect of $P$. vivax infection on erythropoiesis. Enhancing the understanding of the pathogenesis of anaemia caused by malaria is a prerequisite for developing effective prevention and treatment strategies.

\section{Methods}

\section{Collection and separation of Plasmodium vivax parasites}

Plasmodium vivax was obtained from patients attending the malaria clinic in Mae Sot, Tak Province, Thailand. Patient blood with $0.1-0.3 \%$ parasitaemia, as determined by examining thick and thin blood smears, was collected. The ethical and methodological aspects of this study for parasite collection (MU-IRB 2010/344.1612) have been approved by the Mahidol University Institutional Review Board, Mahidol University, Bangkok, Thailand. Infected erythrocytes (IE) were separated from patient blood using a 60\% Percoll solution as previously described [23]. Briefly, whole blood with vivax parasites was collected and then filtrated using a Plasmodipur filter (Euro-Diagnostic B.V., Netherlands) to remove white blood cells. To obtain asexual parasites, packed, infected RBCs from $20 \mathrm{ml}$ of patient blood was diluted 1:2 with RPMI1640 (Invitrogen ${ }^{\circledR}, \mathrm{CA}, \mathrm{USA}$ ), layered on $60 \%$ Percoll and centrifuged at $1,200 \mathrm{~g}$ for $20 \mathrm{mins}$ at $20^{\circ} \mathrm{C}$. The purity of IE after isolation was $95 \%$ and the pure fraction of isolated IE contained $80 \%$ schizontes and $20 \%$ of other stages. The isolated IEs were used either intact or as lysed cells prepared by freezing and thawing.

\section{Isolation of cord blood CD $34^{+}$cells and culture conditions}

Umbilical cord blood from normal full-term deliveries in Ramathibodi Hospital, Bangkok, Thailand was collected into cord blood bags containing anticoagulant solution (CPDA-1 solution) (Kawasumi Laboratories, Thailand). Cord blood collection (ID 04-45-16) was approved by the Ethical Committee of Research on Human Beings of the Ramathibodi Hospital, Faculty of Medicine, Mahidol University. Haematopoietic stem cells/CD34 ${ }^{+}$cells were isolated from cord blood mononuclear cells (MNC) using a CD 34 isolation kit with magnetic microbead selection with Mini-MACS columns (Miltenyi Biotech, Geramany) as described by Panichakul et al [23]. The purity of $\mathrm{CD}_{34}{ }^{+}$cells after isolation was $97 \%$ as judged by flow cytometry analysis.

$\mathrm{HSCs} / \mathrm{CD} 34^{+}$cells at a density of $1 \times 10^{5} \mathrm{cell} /$ well in 24-well tissue culture plates (Corning Incorporated $\operatorname{Costar}^{\circledR}$, NY, USA) were cultured in $0.5 \mathrm{ml}$ of complete medium containing StemlineII medium (Sigma-Aldrich Corporation, Missouri, USA) supplemented with cytokines [23]. IE at the indicated concentration were added to cell cultures on days $1,5,8$ and 11 and cultured for three additional days. Intact and lysed IE from the same patients were utilized in this study. Recombinant human tumour necrosis factor-alpha (TNF-a), human interferon gamma (IFN-g) (Prospec-Tany TechnoGene Ltd., Rehovot, Israel), and uninfected erythrocytes (UE) from normal donor blood were included in this study. All cultures were incubated at $37^{\circ} \mathrm{C}$ in $5 \% \mathrm{CO}_{2}$ and viable cells were determined by trypan blue dye exclusion.

\section{Detection of surface markers of erythroid cells}

Cell surface markers were detected using immunofluorescence with mouse antibodies to human CD34 (Miltenyi Biotech), CD71, CD45 (eBioscience, Inc. CA, USA) and glycophorin A (Serotec Inc., NC, USA) to confirm cell types of HSC and derived erythroid cells. Cells (5$10 \times 10^{4}$ cells in $100 \mu \mathrm{l}$ of medium) were stained with $5 \mu \mathrm{l}$ of each antibody for $30 \mathrm{~min}$ at $4^{\circ} \mathrm{C}$. After washing twice with phosphate-buffer saline, stained cells were fixed with $1 \%$ paraformaldehyde. Cell death was also determined by staining with $20 \mu \mathrm{g} / \mathrm{ml}$ of propidium iodide (BenderMedSystems $\left.{ }^{\circledR}, \mathrm{GmSH}\right)$. All cell markers were analysed by flow cytometry using an Epics XL-MCL analyser (Beckman Coulter, Inc. CA, USA).

\section{Determination of inflammatory cytokines}

The presence of inflammatory cytokines TNF-a and IFN-g in culture medium of gEC was determined using the Bio-Plex Pro Magnetic Cytokine assay (Bio-Rad Laboratories, Inc. CA, USA). Briefly, $50 \mu \mathrm{l}$ of beads coated with different anti-cytokine antibodies were added to a pre-wet filter plate and after washing $50 \mu \mathrm{l}$ of culture medium or cytokine standards were added to duplicate wells and incubated for $30 \mathrm{~min}$ at room temperature in the dark. The plate was washed three times with washing buffer and $50 \mu \mathrm{l}$ of streptavidin-PE was added and 
the reaction was incubated for $10 \mathrm{~min}$. Following three washes, $125 \mu \mathrm{l}$ of assay buffer was added and the plate was analysed immediately using an array reader (BioPlex Manager 5.0 Software, Bio-Rad Laboratories).

\section{Cell division assay}

Five-day old cells were exposed to lysed IE for three days followed by incubation with $3 \mu \mathrm{g} / \mathrm{ml}$ cytochalasin B (Sigma-Aldrich Corporation) for $24 \mathrm{~h}$ as previously described [24]. Cells $\left(5-10 \times 10^{4}\right.$ in $100 \mu \mathrm{l}$ of medium) were spun onto a slide using cytospin (Cytospin 3, Thermo Shandon, UK) at $800 \mathrm{rpm}$ for $10 \mathrm{~min}$ then fixed with $95 \%$ ethanol for $10 \mathrm{~min}$. Thereafter, cells were stained for $10 \mathrm{~min}$ with Giemsa, then washed and dried. Stained cells were examined under a light microscope (Olympus BX50, Japan) and the proportion of mono-, bi-, tri- and tetranucleated cells was evaluated in samples of 2,000 cells. The Cytokinesis Block Proliferation Index (CBPI) was calculated using the formula $C B P I=X$ $(1 \mathrm{~N})+\mathrm{Y}(2 \mathrm{~N})+\mathrm{Z}(3 \mathrm{~N}) / \mathrm{X}+\mathrm{Y}+\mathrm{Z}$; where $\mathrm{X}, \mathrm{Y}$ and $\mathrm{Z}$ are the number of cells with one, two and three nuclei $(\mathrm{N})$, respectively [25].

\section{Statistical evaluation}

Data were analysed using the SPSS program (version 11.0). The unpaired Mann-Whitney - Wilcoxon test was used to compare means between independent groups as appropriate and for statistical evaluation of CBPI. Results are reported as statistically significant if the $P$ value was less than 0.01 .

\section{Results}

\section{Inhibition of cell growth by Plasmodium vivax}

Growing erythroid cells (gEC) derived from human cord blood HSCs $/ \mathrm{CD} 4^{+}$cells were used as an in vitro model for studying changes in erythropoiesis caused by $P$. vivax infection. Infected erythrocytes (IE) were isolated from the blood of malaria patients and the effect of the presence of IE on erythroid growth was determined as shown in Figure 1a. The effect of lysates from IE was
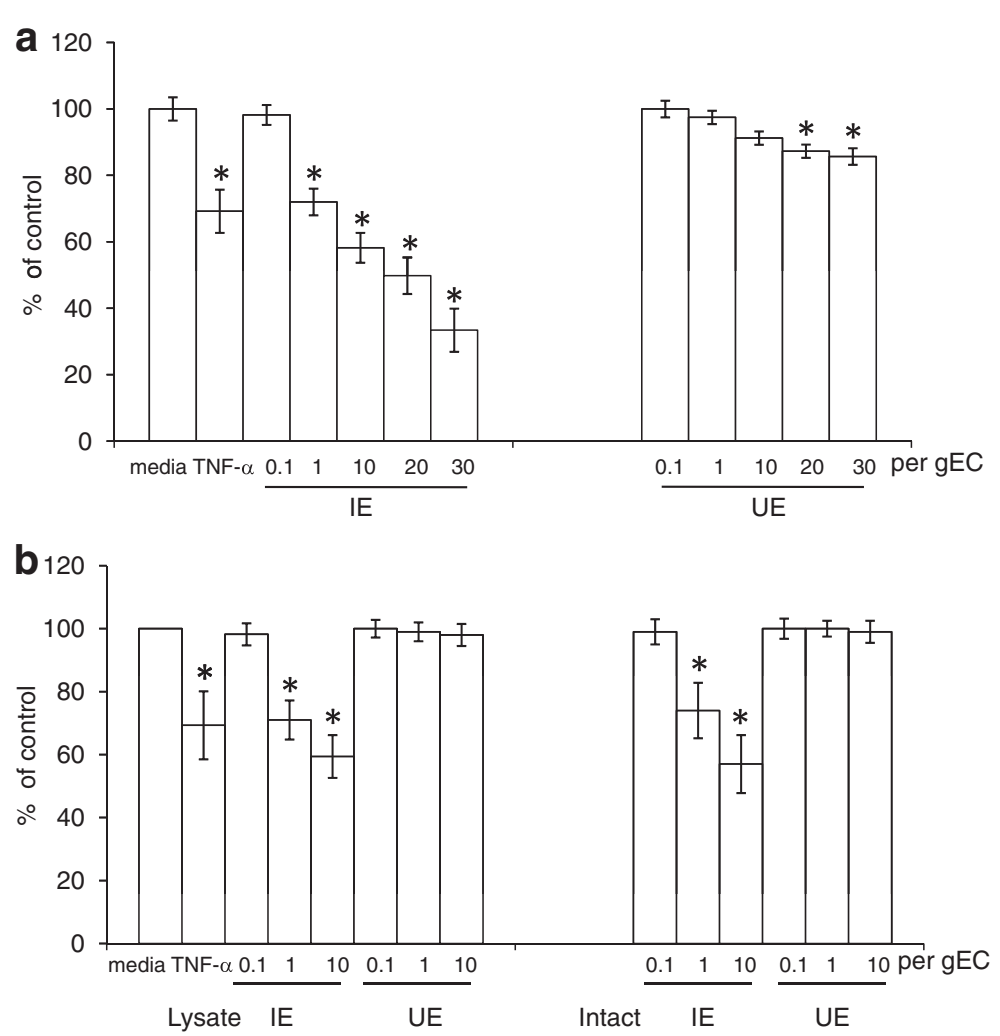

Figure 1 Effect of $P$. vivax on cell growth. (a) Lysates of infected erythrocytes (IE) or uninfected erythrocytes (UE) and (b) lysed IES or UES and intact IEs or UEs were added in varying ratios of IE numbers to one growing erythroid cells (gEC) on day 5. Erythroid growth was evaluated on day 8. The mean of erythroid growth (shown in bar graphs) was compared with a control containing medium without IE or UE lysate. $25 \mathrm{ng} / \mathrm{ml}$ of TNF-a was used as a positive control. The error bars show the S.D. of 5 independent experiments, $P$-value $<0.01$ compared with medium control. 
compared with those from uninfected erythrocytes (UE) on gEC cultures by treating cells on day-5 with five ratios of IE/UE: gEC (0.1:1, 1:1, 10:1, 20:1 and 30:1). After culturing gEC for another three days, parasiteinduced inhibition of erythroid growth was monitored and ratios as low as 1 lysed IE to 1 gEC were found to cause a dose-dependent decrease in growth (Figure 1a). The effect of lysed and intact IE on erythroid growth was evaluated and is shown in Figure 1b. Lysed and intact IE or UE were added on day 5 of gEC cultures and their effects on day 8 were compared. Both lysed and intact IE at a IE : gEC ratio of 10:1 significantly inhibited the erythroid growth however addition of UE did not alter growth. The reduction of erythroid growth did not differ significantly between intact and lysed IE with the mean growth relative to controls without lysed or intact IE was $59.4 \pm 5.2$ for lysed IE and $57 \pm 8.5 \%$ for intact IE. These results demonstrated that there was no metabolic effect of viable infected cells on erythroid cell growth. Similar results were obtained with infected erythrocytes from five different parasite isolates. Overall these results demonstrate that lysed IE with low numbers of $P$. vivaxinfected cells are sufficient to inhibit the growth of erythroid cells.

\section{Inhibition of erythroid development}

The inhibition of erythroid expansion and differentiation by $P$. vivax was evaluated in the presence of IE and UE. Lysed IE or UE were mixed with isolated CD $34^{+}$cells/ erythroid progenitor cells on day 1, 5, 8 and 11 after induction of erythroid development. After three days, lysed IE inhibited erythroid expansion, compared with the controls (Table 1). The effect was greatest when a ratio of 10 IE to one erythroid precursor was used on day-1 resulting in reduction of erythroid growth to $43 \pm 5.5 \%$ compared with controls without IE. The degree of inhibition of erythroid expansion by IE on days

\section{Table 1 Inhibition of erythroid expansion by lysate of infected erythrocytes to $\mathrm{CD} 34^{+}$cells /erythroid progenitor cells}

\begin{tabular}{|c|c|c|c|c|c|}
\hline \multirow{3}{*}{$\begin{array}{l}\text { Day-old } \\
\text { of cell } \\
\text { cultures }\end{array}$} & \multicolumn{5}{|c|}{$\%$ of control (mean \pm S.D.) } \\
\hline & IE & IE & UE & UE & TNF-a \\
\hline & 1 & 10 & 1 & 10 & $25 \mathrm{ng} / \mathrm{m}$ \\
\hline 1 & $67 \pm 9.5^{*}$ & $43 \pm 5.5^{*}$ & $100 \pm 4.5$ & $98 \pm 5.5$ & $54 \pm 12^{*}$ \\
\hline 5 & $72 \pm 6.5^{*}$ & $58 \pm 4.5^{*}$ & $99 \pm 4.0$ & $98 \pm 4.8$ & $69 \pm 8^{*}$ \\
\hline 8 & $88 \pm 4.5$ & $65 \pm 7.5^{*}$ & $99 \pm 2.0$ & $99 \pm 5.5$ & $74 \pm 7^{*}$ \\
\hline 11 & $98 \pm 8.5$ & $87 \pm 7.0^{*}$ & $100 \pm 4.5$ & $100 \pm 5.0$ & $78 \pm 6^{*}$ \\
\hline
\end{tabular}

* P-value $<0.01$ compared with control wells.

Inhibition is presented as percentage of expansion of the control after three day-culture without added medium, cells, or TNF-a. Lysates of infected erythrocyte (IE) and uninfected erythrocyte (UE) were added at ratios of 1 or $10 \mathrm{IE} / \mathrm{UE}$ per $1 \mathrm{CD} 34^{+}$cells / erythroid progenitor cells. The mean and S.D. were calculated from five independent experiments.
5, 8 and 11 was gradually decreased but still significant $(P$-value $<0.01)$ indicating that $\mathrm{CD} 34^{+} /$erythroid progenitor cells were susceptible to the inhibitory effect of $P$. vivax on cell expansion. The susceptibility to the inhibitory effect of $P$. vivax was decreased when cells were mature as shown in Additional file 1. In addition, a reduction in erythroid cell development was supported by the observed decrease in the expression of erythroblast markers, $28.1 \%$ of glycophorin A and $43.9 \%$ of CD 71 after three days of culture with IE lysates compared to controls without IE which expressed 50\% of glycophorin $\mathrm{A}$ and $72.1 \%$ of CD 71 (Figure 2a). Cell death was also determined and found to occur at similar levels in cultures with IE lysate $(5.9 \pm 1.2 \%)$ or media alone $(4.1 \pm 1 \%)$, after three days of culture (Figure $2 \mathrm{~b}$ ). This indicates that the reduction of erythroid cells when exposed to IE lysates was not from death activation from parasites but rather that parasites suppress erythropoiesis through an inhibitory effect on expansion of CD34 $4^{+}$erythroid progenitor cells.

\section{Suppression of cell division by Plasmodium vivax}

Cytokinesis Block Proliferation Index (CBPI) is a useful parameter for assessing the inhibition of cell division in cultures. To examine the inhibition of erythroid division by $P$. vivax, lysed IE were added to five-day old gEC cultures and after three days cell division was blocked by cytochalasin B. In controls, treated with media or UE lysates, large numbers of bi-nucleated cells were observed with few tri- and tetra-nucleuated gEC. In contrast, cultures exposed to IE lysates contained high numbers of mono-nucleus gEC (Figure 3a). Cultures undergoing parasite-suppression due to exposure with IE lysates displayed a significant reduction $(P$-value $<0.01)$ in the CBPI $(1.35 \pm 0.05$; mean \pm S.D. $)$ compared with gEC in media control $(2.08 \pm 0.07)$ as shown in Figure 3b. The CBPI of cultures treated with UE lysate and TNF-a were $2.0 \pm 0.06$ and $1.74 \pm 0.04$, respectively. These results suggest that vivax parasites inhibited expansion of erythroid progenitor cells by blocking cellular division.

In patients with vivax malaria, TNF-a and IFN-g have been associated with malaria anaemia and may be involved in promoting inadequate erythropoiesis. In this model system, gEC cells were treated with recombinant human TNF-a or IFN-g in various concentrations and the erythroid cell growth was inhibited at TNF-a and IFN-g concentrations 6.25 and $100 \mathrm{ng} / \mathrm{ml}$, respectively (Figure 4a). However, after adding lysed or intact IE to the gEC cultures on day 5 endogenous TNF-a was undetectable after three days of parasite activation (Figure 4b), even though the lower limit of detection in this assay was $5 \mathrm{pg} / \mathrm{ml}$. Another cytokine, IFN-g, was also undetectable in medium cultured with intact or lysed IE. However, IFN-g could be detected in cultures treated 

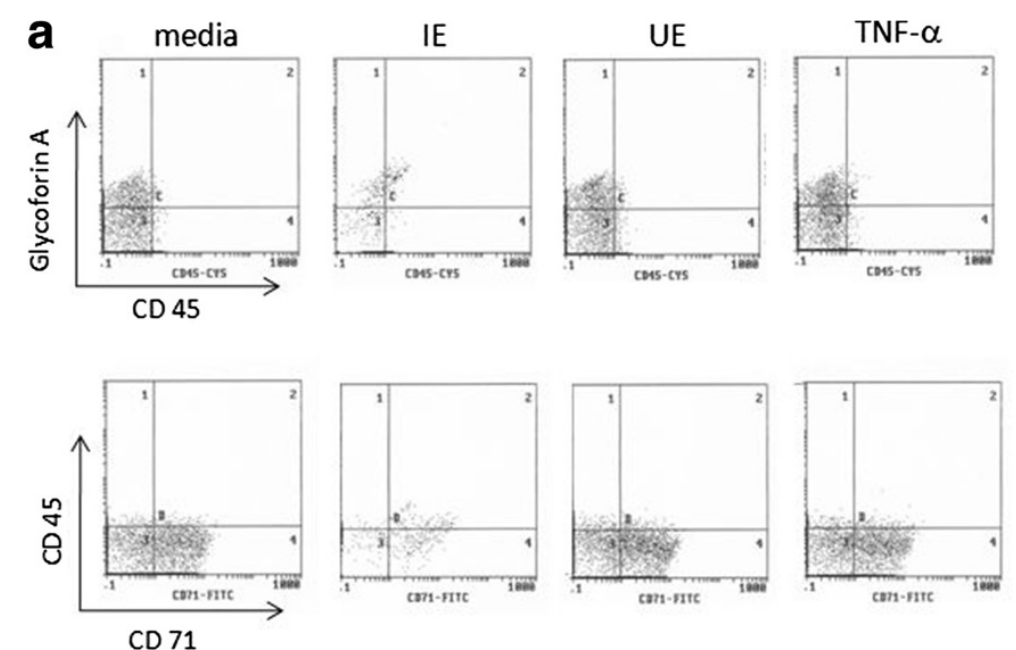

CD 71

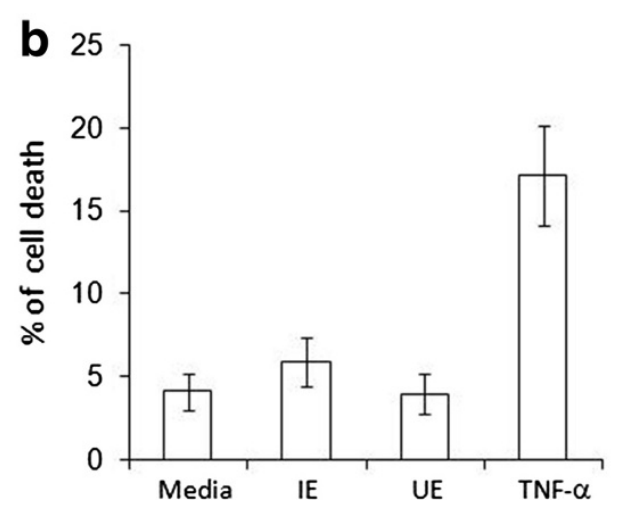

Figure 2 Determination of erythroid cell markers and death. gECs, five-days old were cultured with IE or UE lysate in the ratio 1:10. Cell markers were determined after culturing for another three days by flow cytometry. (a) Dot-scatter graphs of erythroid cell markers, using fluorescence-labelled anti-glycophorin A, CD 45 and CD 71 antibodies, and (b) cell death, using propidium iodide (PI) staining. The error bars of histograms show the S.D. of three independent experiments.

with $25 \mathrm{ng} / \mathrm{ml}$ of TNF-a, as shown in Figure 4b. The lower limit of IFN-g detection in this assay was $26 \mathrm{pg} /$ $\mathrm{ml}$. Therefore, in this model, parasites inhibited erythroid development in a way that was independent of TNF-a and IFN-g.

\section{Discussion}

Numerous reports have shown that $P$. vivax can be associated with severe anaemia [2-12]. Haematologic profiles of pancytopaenia in blood and bone marrow [16] and dyserythropoiesis in bone marrow [15] have been reported in vivax malaria patients. However, the cause of reduction in blood cell production in the bone marrow of patients with vivax malaria is not completely understood. Anaemia in malaria is caused by excessive removal of non-parasitized erythrocytes, the immune destruction of parasite-infected red cells, as well as by the impaired compensation due to bone marrow dysfunction [1,15,17,26-28]. Plasmodium vivax requires reticulocytes for expansion of the blood stages [29] and parasitaemia is generally low, therefore it is unlikely to be the primary cause of anaemia [6]. This suggests that in addition to the simple destruction of infected red cells another mechanism is involved in anaemia in vivax malaria.

Recently, the production of erythrocytes from the in vitro cultures of haematopoietic stem cells was achieved, as previously described [23] and this model is now being applied to dissect the complexity of anaemia in malaria. The results presented in this study have revealed for the first time that $P$. vivax can directly inhibited erythropoiesis, as shown by the reduction of erythroid growth in the presence of either lysed or intact IE. Erythroid progenitor cells were susceptible to the inhibitory effect of $P$. vivax on cell expansion and this result is consistent with the previous report that young stages of erythroid cells were more susceptible to $P$. vivax infection [23]. The suppression of erythropoiesis in malarial anaemia is not unique to $P$. vivax and has also been observed in infections from other 


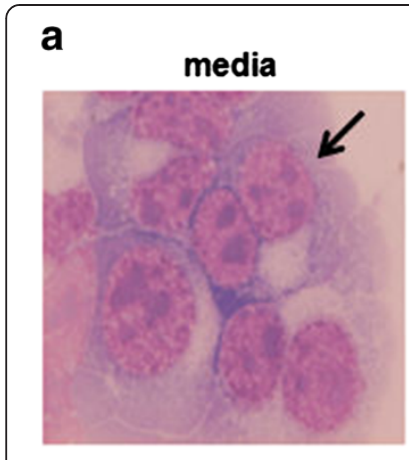

UE

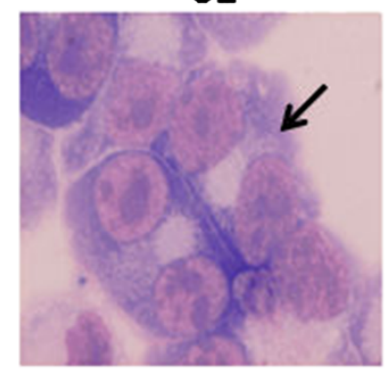

b

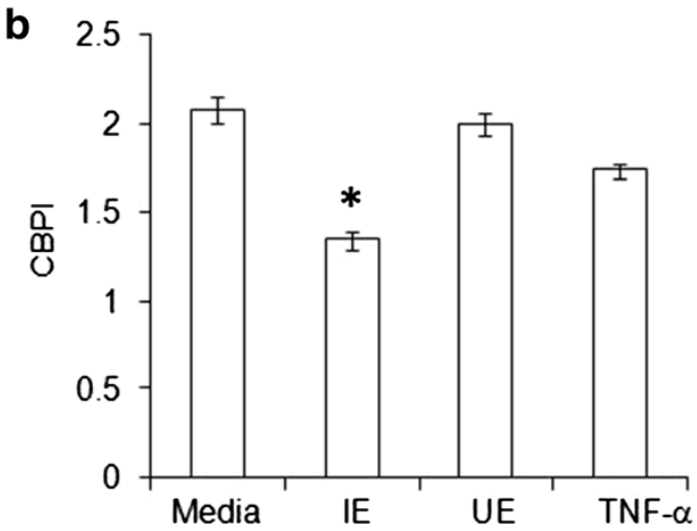

Figure 3 Reduction of cell division by $P$. vivax. Five-day old growing erythroid cells (gECs), $10^{5}$ cells, in cultures with added media, lysates of $10^{6}$ infected cells (IE) or uninfected cells (UE) and TNF-a were incubated for 72 h. (a) Cells stained with Giemsa, binucleuses in gECs are indicated with arrows, magnification $X$ 1,000. (b) CBPI (cytokinesis block proliferation index) of gEC cultures after added cytochalasin B. The error bars represent the S.D. for five independent experiments, ${ }^{*} P$-value $<0.01$.

Plasmodium species. In the complicated Plasmodium falciparum infection, erythroid suppression is indicated by a decrease in the number of erythroid precursors as well as colony-forming units-erythroid (CFU-E) and burst-forming units-erythroid (BFU-E) in the bone marrow cultures [30]. Plasmodium chabaudi can directly suppress the proliferation, differentiation and maturation of erythroid progenitor cells and causes inadequate reticulocytosis in mice [31]. However, deficient erythropoietin production does not appear to be the cause of inadequate erythropoiesis in malaria [32].
Decreased responsiveness of erythroid progenitor cells to erythropoietin as well as impaired erythropoietin production mediated by inflammatory cytokines has been reported to be involved in anaemia during inflammation [33]. Consistent with this observation, TNF-a was reported to partly inhibit proliferation of erythroid progenitor cells in bone marrow cultures [34]. Erythroid progenitor cells produced in this model were also susceptible to inhibition by exogenous TNF-a as shown in Figure 4a. However, endogenous TNF-a and IFN-g in erythroid cultures exposed to lysates or intact $P$. vivax was undetectable (Figure 4b). This suggests that $P$. vivax can also inhibit erythropoiesis independently of TNF-a and IFN-g. Inhibition of erythroid development that is independent of TNF-a and IFN-g has also been observed by exposure with $P$. falciparum haemozoin [35,36]. However, other inflammatory cytokines may be involved and high levels of IL-10 were found to correlate positively with inhibition of proliferative peripheral blood mononuclear cells in the presence of P. falciparum haemozoin [37]. In this study, IL-10 was also detectable in supernatants from gECs in the presence of IEs and the role of this cytokine in the inhibition of erythropoiesis is currently being investigated. Interestingly, $P$. vivax inhibited not only growth but also the differentiation of erythroid progenitor cells as shown by the reduction of glycophorin $^{+}$and $C D 71^{+}$cells and this is similar to the inhibitory effect of $P$. falciparum haemozoin on erythroid cell development [35,38]. Moreover, vivax parasites were able to perturb the cell division but did not induce the cell death of erythroid progenitor cells. Defects in the cell cycle without apoptosis has also been observed with the inhibitory effect of $P$. falciparum haemozoin on erythroid cell growth [38]. It was found that falciparum haemozoin-treated erythroid cells enhanced the expression of the transcription factor p53 and cdk-inhibitor p21 in addition the retinoblastoma protein, a central regulator of G- to S-phase transition was hypophosphorylated, while GATA-1, the master transcription factor in erythropoiesis was reduced [38]. Therefore the molecular mechanisms underlying the suppression of erythropoiesis by $P$. vivax or its products warrants further investigation. The findings of this study are consistent with the hypothesis that vivax parasites can suppress erythropoiesis. These results provide a better understanding of the role of chronic and persistent $P$. vivax infection as a cause of anaemia. Prolonged exposure to vivax parasites can suppress erythropoiesis as well as inhibit reticulocyte production, which could prevent the restoration of the erythrocyte population in chronic parasitaemic $P$. vivax infection. Many cases of patients with severe anaemia have been reported in vivax endemic areas in Thailand, Indonesian Papua, Korea, Pakistan, Venezuela, and Colombia $[3,5,7,9,10,14]$. These patients 

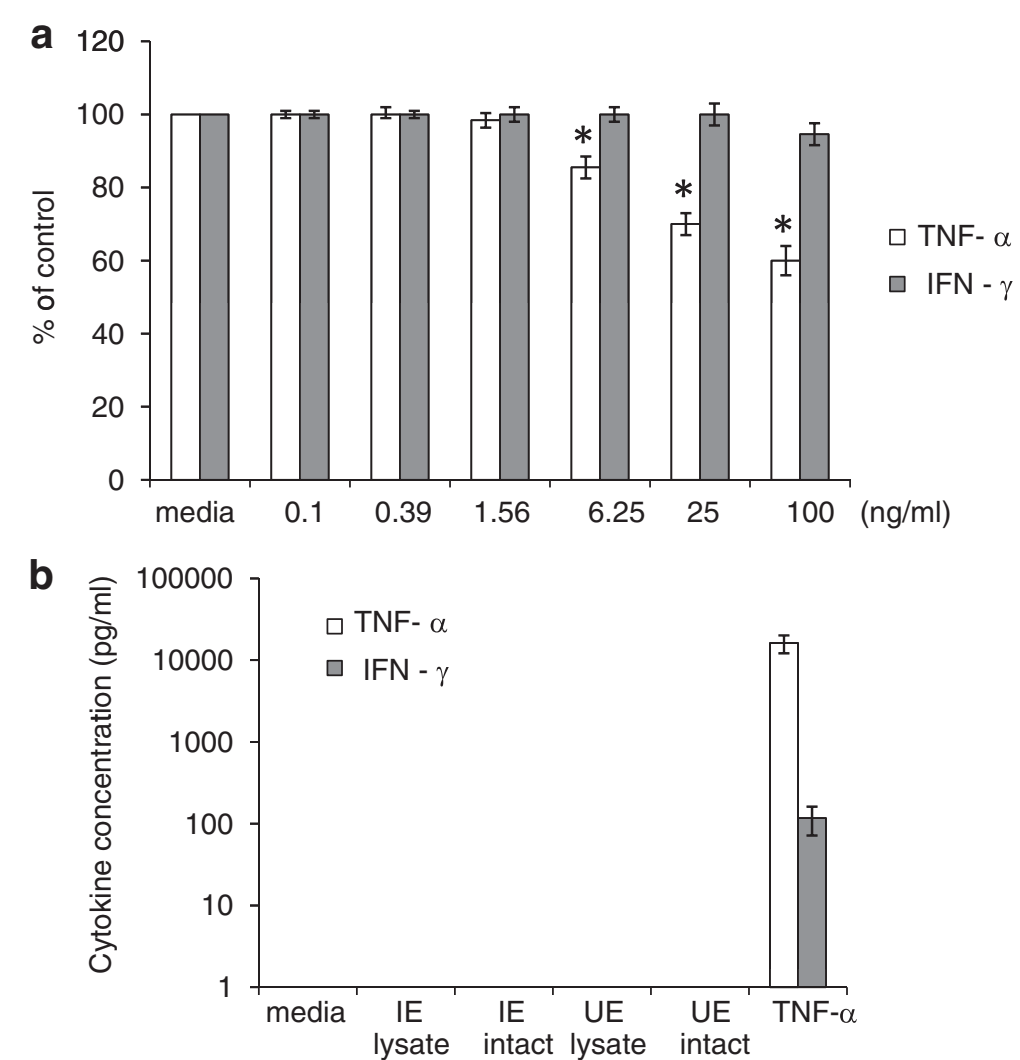

Figure 4 Effect of inflammatory cytokines on erythroid cell growth. (a) Growing erythroid cells (gECs) 5-days old were treated with various concentrations of TNF-a (white bars) or IFN-g (grey bars) and cultured for an additional three days. * $P<0.01$ compared with medium control. (b) TNF-a (white bars) and IFN-g (grey bars) in erythroid culture activated by intact IEs or UEs; lysates of IEs or UEs; and $25 \mathrm{ng} / \mathrm{ml}$ of TNF-a as a positive control were determined using the Bio-Plex Pro ${ }^{\mathrm{mm}}$ Magnetic Cytokine assay. The error bars show the S.D. from three independent experiments.

are often infected or re-infected with the vivax parasites and parasites have the potential to inhibit erythroid development leading to ineffective erythropoiesis causing severe anaemia.

\section{Conclusions}

This finding suggests that suppression of erythropoiesis by $P$. vivax infection is potentially much more dangerous than it is commonly believed and defective erythropoiesis should be taken into consideration in the development of therapeutic strategies to treat severe malarial anaemia.

\section{Additional file}

Additional file 1: Erythroid cell development. Giemsa staining of cells from one to 11 day-old cultures showing CD34 $4^{+}$cells on day 1, and morphological characteristic of erythroid cells with haemoglobin and chromatin condensation for an orthochromic normoblasts (arrow) on day 11. Magnification X 1,000.

\section{Abbreviations}

HSC: Haematopoietic stem cell; MNC: Mononuclear cell; IE: Infected erythrocyte; UE: Uninfected erythrocyte; gEC: Growing erythroid cell;
TNF-a: Tumour necrosis factor-alpha; IFN-g: Interferon-gamma; CBPI: Cytokinesis block proliferation index; CFU-E: Colony-forming unitserythroid; BFU-E: Burst-forming units-erythroid.

\section{Competing interests}

The authors declare that they have no competing interests.

\section{Acknowledgements}

This study was supported by Thailand Research Fund, Commission on Higher Education, Ministry of Education and Suan Dusit Rajabhat University, (MRG5380092), the Office of the Higher Education Commission, and Mahidol University under the National Research Universities Initiative. I would like to thank the Mahidol Vivax Research Center, Faculty of Tropical Medicine for parasite collection, Ramathibodi Hospital, Faculty of Medicine for providing cord blood specimens, the Department of Pathobiology, Faculty of Science for excellent technical assistance, and Dr Laran Jensen, Department of Biochemistry, Faculty of Science, Mahidol University, Bangkok Thailand for critical reading of this manuscript.

\section{Author details}

${ }^{1}$ Faculty of Science and Technology, Suan Dusit Rajabhat University, 204/3 Sirindhorn Rd., Bangplat, Bangkok, 10700, Thailand. ²Department of Pathobiology, Faculty of Science, Mahidol University, 272 Rama VI RoadRatchathewi DistrictBangkok, 10400, Thailand. ${ }^{3}$ Department of Obstetrics and Gynaecology, Faculty of Medicine, Ramathibodi Hospital, Mahidol University, 272 Rama VI RoadRatchathewi DistrictBangkok, 10400, Thailand. ${ }^{4}$ Research Center, Faculty of Medicine, Ramathibodi Hospital, Mahidol University, 272 Rama VI RoadRatchathewi DistrictBangkok, 10400, Thailand. ${ }^{5}$ Department of Pediatric, Faculty of Medicine, Ramathibodi Hospital, Mahidol 
University, 272 Rama VI RoadRatchathewi DistrictBangkok, 10400, Thailand ${ }^{6}$ Center for Emerging and Neglected Infectious Diseases, Mahidol University, 999999 Phuttamonthon 4 Road, Salaya, Nakhon Pathom 73170, Thailand.

\section{Authors' contributions}

TP designed the study, collected vivax parasites from patients, performed experiment and statistical analysis, and wrote the manuscript. WP isolated human $\mathrm{CD}_{3} 4^{+}$cells and cultured cells. PP collected human cord blood from normal full-term deliveries. CW performed analysis of cell markers and cytokine assay. SH and RU contributed substantially to the design of the study and critically revised the manuscript. All authors read and approved the final manuscript.

Received: 29 February 2012 Accepted: 24 May 2012

Published: 24 May 2012

\section{References}

1. Sina B: Focus on Plasmodium vivax. Trends Parasitol 2002, 18:287-289

2. Selvam R, Baskaran G: Hematological impairments in recurrent Plasmodium vivax infected patients. Jpn J Med Sci Biol 1996, 49:151-165.

3. Luxemburger C, Ricci F, Raimond D, Bather S, White NJ: The epidemiology of severe malaria in an area of low transmission in Thailand. Trans $R$ Soc Med Hyg 1997, 91:256-262

4. Mohapatra MK, Padhiary KN, Mishra DP, Sethy G: Atypical manifestations of Plasmodium vivax malaria. Indian J Malariol 2002, 39:18-25.

5. Song HH, O SO, Kim SH, Moon SH, Kim JB, Yoon JW, Koo JR, Hong KS, Lee MG, Kim DJ, Shin DH, Kang SH, Choi MG, Lee KH: Clinical features of Plasmodium vivax malaria. Korean J Intern Med 2003, 18:220-224.

6. Collins WE, Jeffery GM, Roberts JM: A retrospective examination of anemia during infection of humans with Plasmodium vivax. Am J Trop Med Hyg 2003, 68:410-412

7. Echeverri M, Tobón A, Alvarez G, Carmona J, Blair S: Clinical and Laboratory findings of Plasmodium vivax malaria in Colombia, 2001. Rev Inst Med Trop Sao Paulo 2003, 45:29-34.

8. Kochar DK, Saxena V, Singh N, Kochar SK, Kumar SV, Das A: Plasmodium vivax malaria. Emerging Infect Dis 2005, 11:132-134.

9. Kochar DK, Das A, Kochar SK, Saxena V, Sirohi P, Garg S, Kochar A, Khatri MP, Gupta V: Severe Plasmodium vivax malaria: a report on serial cases from Bikaner in northwestern India. Am J Trop Med Hyg 2009, 80:194-198.

10. Rodriguez-Morales AJ, Sanchez E, Vargas M, Piccolo C, Colina R, Arria M: Anemia and thrombocytopenia in children with Plasmodium vivax malaria. J Trop Pediatr 2005, 52:49-51.

11. Baird JK: Neglect of Plasmodium vivax malaria. Trends Parasitol 2007, 23:533-539.

12. Genton B, Acremont VD, Rare L, Baea K, Reeder JC, Alpers MP, Muller I: Plasmodium vivax and mixed infections are associated with severe malaria in children: a prospective cohort study from Papua New Guinea. PLoS Med 2008, 5:881-889.

13. Beg MA, Khan R, Baig SM, Gulzar Z, Hussain R, Smego RA JR: Cerebral involvement in benign tertian malaria. Am J Trop Med Hyg 2002, 67:230-232

14. Barcus MJ, Basri H, Picarima H, Manyakori C, Sekartuti M, Elyazar I, Bangs MJ, Maguire JD, Baird JK: Demographic risk factors for severe and fetal vivax and falciparum malaria among hospital admissions in Northeastern Indonesian Papua. Am J Trop Med Hyg 2007, 77:984-991.

15. Wickramasinghe SN, Abdalla SH: Blood and bone marrow changes in malaria. Baillieres Best Pract Res Clin Haematol 2000, 13:277-299.

16. Yamakawa $H$, Kiyotaki $M$, Hattori $Y$, Obana M, Matsuoka $Y$, Irimajiri S: A case of Plasmodium vivax malaria complicated with pancytopenia due to hypoplasia of the bone marrow. Kansenshogaku Zasshi 1989, 63:1043-1046.

17. Wickramasinghe SN, Looareesuwan S, Nagachinta B, White NJ: Dyserythropoiesis and ineffective erythropoiesis in Plasmodium vivax malaria. Br J Haematol 1989, 72:91-99.

18. Andrade BB, Reis-Filho A, Souza-Neto SM, Clarencio J, Camargo LMA, Barra A, Barral-Netto M: Severe Plamodium vivax malaria exhibits marked inflammatory imbalance. Malaria J 2010, 9:1-8.

19. Clark IA, Chaudhri G: Tumor necrosis factor may contribute to the anaemia of malaria by causing dyserythropoiesis and erythrophagocytosis. Br J Haematol 1988, 70:99-103.

20. Greve B, Kremsner PG, Lell B, Luckner D, Schmid D: Malarial anaemia in African children associated with high oxygen-radical production. Lancet 2000, 355:40-41.
21. Kun JF, Mordmuller B, Perkins DJ, May J, Mercereau-Puijalon O, Alpers M, Weinberg JB, Kremsner PG: Nitric oxide synthase 2 (Lambarene) (G-954 C), increased nitric oxide production, and protection against malaria. J Infect Dis 2001, 184:330-336.

22. Schwarzer E, Turrini F, Ulliers D, Giribaldi G, Ginsburg $H$, Arese $P$ : Impairment of macrophage functions after ingestion of Plasmodium falciparum-infected erythrocytes or isolated malarial pigment. J Exp Med 1992, 176:1033-1041.

23. Panichakul T, Sattabongkot J, Chotivanich K, Sirichaisinthop J, Cui L, Udomsangpetch R: Production of erythropoietic cells in vitro for continuous culture of Plasmodium vivax. Int J Parasitol 2007, 37:1551-1557

24. Surrallhs J, Antoccia A, Creus A, Degrassi F, Peris F, Tanzarella C, Xamena N, Marcos R: The effects of cytochalasin-B concentration on the frequency of micronuclei induced by four standard mutagens. Results from two laboratories. Mutagenesis 1994, 9:347-353.

25. Surrallhs J, Xamena N, Ceus A, Catalan J, Norppa H, Marcos R: Induction of micronuclei by five pyrethroid insecticides in whole blood and isolated human lymphocyte cultures. Mutat Res 1995, 341:169-184.

26. Dondorp AM, Angus BJ, Chotivanich K, Silamut K, Ruangveerayuth R, Hardeman MR, Kager PA, Vreeken J, White NJ: Red blood cell deformability as a predictor of anemia in severe falciparum malaria. Am J Trop Med Hyg 1999, 60:733-737.

27. Egan AF, Fabucci ME, Saul A, Kaslow DC, Miller LH: Aotus New World monkeys: model for studying malaria-induced anemia. Blood 2002, 99:3863-3866.

28. Facer CA: Direct Coombs antiglobulin reactions in Gambian children with Plasmodium falciparum. II. Specificity of erythrocyte-bound IgG. Clin Exp Immunol 1980, 39:279-288.

29. Mons B, Croon JJAB, der Star WV, der Kaay HJV: Erythrocytic schizogony and invasion of Plasmodium vivax in vitro. International J Parasitol 1988 18:307-311

30. Jootar S, Chaisiripoomkere W, Pholvicha P, Leelasiri A, Prayoonwiwat W, Mongkonsvitragoon W, Srichaikul T: Suppression of erythroid progenitor cells during malarial infection in Thai adults caused by serum inhibitor. Clin Lab Haematol 1993, 15:87-92.

31. Chang KH, Tam M, Stevenson MM: Inappropriately reticulocytosis in severe malaria anemia correlates with suppression in the development of late erythroid precursors. Blood 2004, 103:3727-3735.

32. Chang $\mathrm{KH}$, Stevenson MM: Malaria anemia: mechanisms and implications of insufficient erythropoiesis during blood-stage malaria. Int J Parasitol 2004, 34:1501-1516.

33. Kurtzhals JA, Rodrigues O, Addae M, Commey JO, Nkrumah FK, Hviid L: Reversible suppression of bone marrow response to erythropoietin in Plasmodium falciparum malaria. Br J Haematol 1997, 97:169-174.

34. Roodman GD, Bird A, Hutzler D, Montgomery W: Tumor necrosis factoralpha and hematopoietic progenitors: effects of tumor necrosis factor on the growth of erythroid progenitors CFU-E and BFU-E and the hematopoietic cell lines K562, HL60, and HEL cells. Exp Hematol 1987, 15:928-935

35. Casals-Pascual C, Kai O, Cheung JO, Williams S, Lowe B, Nyanoti M, Williams TN, Maitland K, Molyneux M, Newton CR, Peshu N, Watt SM, Roberts DJ: Suppression of erythropoiesis in malarial anemia is associated with hemozoin in vitro and in vivo. Blood 2006, 108:2569-2577.

36. Lamikanra AA, Theron M, Kooij TWA, Roberts DJ: Hemozoin (Malaria pigment directly promotes apoptosis of erythroid precursors). PLoS One 2009, 4:e8446.

37. Deshpande P, Shastry P: Modulation of cytokine profiles by malaria pigment-hemozoin: role of IL-10 in suppression of proliferative responses of mitogen stimulated human PBMC. Cytokine 2004, 28:205-213.

38. Skorokhod CA, Caione L, Marrocco T, Migliard G, Barrera V, Arese P, Piacibello W, Schwarzer E: Inhibition of erythropoiesis in malaria anemia: role of hemozoin and hemozoin-generated 4-hydroxynonenal. Blood 2012, 116:4328-4337.

doi:10.1186/1475-2875-11-173

Cite this article as: Panichakul et al:: Suppression of erythroid development in vitro by Plasmodium vivax. Malaria Journal 2012 11:173. 